\title{
Analisa Corrosion Rate dan Remaining Life Pada Storage Tank T-XYZ Berdasarkan API 653 di Kilang PPSDM Migas
}

\author{
Ikhsan Kholis \\ Pusat Pengembangan Sumber Daya Manusia Minyak Dan Gas Bumi, Cepu
}

\begin{abstract}
ABSTRAK
Salah satu peralatan yang banyak terdapat dalam industri migas adalah tangki penimbun. Keberadaan tangki penimbun sangat vital pada produksi industri perminyakan. Sering terjadi kecelakaan yang menimpa tangki timbun dalam industri migas yang menimbulkan kerugian besar. Pada tulisan ini dibahas tentang laju korosi (corrosion rate) dan umur sisa (remaining life) pada fixed cone roof tank, yang terletak di atas tanah (aboveground tank) dalam kondisi in-service dengan API Std $6535^{\text {th }}$ edition 2014 sebagai standar acuan.

Metodeyang digunakan dalam pembahasan diawali dengan studi literatur dari berbagai referensi dan penelitian sebelumnya, kemudian pengambilan data lapangan dan kemudian dianalisa. Dari hasil evaluasi ketebalan dinding tangki di dapat bahwa ketebalan tangki minimum masih relevan atau masih memenuhi persyaratan. Sedangkan hasil analisis menunjukkan laju korosi untuk masing-masing dinding tangki course $1^{\text {st }}$, course $2^{\text {nd }}$ dan course $3^{\text {rd }}$ adalah 0,06, 0,04 dan 0,08 mmpy. Hasil analisis menunjukkan umur sisa untuk masing-masing dinding tangki course $1^{\text {st }}$, course $2^{\text {nd }}$ dan course $3^{\text {rd }}$ adalah $32,67,39,00$ dan 23,25 tahun.

Dari hasil analisa dapat disimpulkan bahwa tangki penimbuna (storage tank) masih layak beroperasi dan masih memenuhi syarat untuk inspeksi berkala 5 tahun yang akan datang dari inspeksi terakhir.
\end{abstract}

Kata kunci: tangki timbun, laju korosi, umur sisa, API Std 653

\section{ABSTRACT}

One of the many equipments utilized in the oil and gas industry is a storage tank. The existence of storage tanks is vital in the production of the oil industry. Accidents often occur on storage tanks in the oil and gas industry which cause huge losses. This paper discusses corrosion rates and remaining life on the existing fixed cone roof tank aboveground in-service conditions with API Std $6535^{\text {th }}$ edition 2014 as the reference standard

The method used in the discussion begins with literature study of various references and previous research, collecting field data and then analyzing it. From the results of the tank shell thickness evaluation, it can be seen that the minimum tank thickness is still relevant or still meets the 
requirements. Meanwhile, the results show that the corrosion for course $1^{\text {st }}$, course $2^{\text {nd }}$ and course $3^{\text {rd }}$ are 0.06, 0.04 and 0.08 mmpy respectively. The results show that the remaining lifes for course $1^{\text {st }}$, course $2^{\text {nd }}$, and course $3^{\text {rd }}$ are $32.67,39.00$ and 23.25 years, respectively.

From the analysis, it can be concluded that the storage tank is still feasible to operate and still meets the requirements of the periodic inspections for the next 5 years from the last inspection.

Keywords: storage tank, corrosion rate, remaining life, API Std 653

\section{PENDAHULUAN}

Tangki penimbun (storage tank) merupakan salah satu peralatan yang sangat vital pada proses produksi industri perminyakan yang berfungi sebagai tempat penyimpanan dan penimbunan bahan cair, baik berupa minyak mentah, produk BBM, hasil minyak olahan, maupun bahan-bahan kimia lainnya. Sering terjadi kecelakaan yang menimpa tangki timbun dalam industri migas, petrokimia dan kimia yang menimbulkan kerugian yang sangat besar. Menurut Almeganews ${ }^{1}$, Berdasarkan data yang dihimpun dari perusahaan asuransi, hampir sekitar 16\% dari kecelakaan besar dalam industri perminyakan selama 30 tahun terakhir menyangkut kebakaran atau peledakan pada tangki timbun, dengan rata-rata kerugian \$ 42,7 juta. Sebagai contoh kebakaran tangki Cilacap mengakibatkan kerugian lebih 75 millyar rupiah. Sehubungan dengan hal tersebut, tangki timbun harus dikelola dan dioperasikan dengan standar keselamatan yang tinggi sejak tahap desain, konstruksi, operasi, pemeliharaan sampai persiapan penanggulangan bila terjadi kejadian yang tidak diinginkan.

Inspeksi tangki penimbun in-service perlu dilakukan agar potensi perubahan kondisi fisik tangki dapat diidentifikasi sebelum terjadinya kegagalan operasi yang disebabkan oleh kecacatan tangki. Metode evaluasi kelayakan operasi (suitability for service) sesuai API Std 653 $5^{\text {th }}$ edition section 4 digunakan dalam inspeksi tangki penimbun.

1 https://almeganews.wordpress.com/2019/08/26/kalibrasitangki-minyak-kelapa-sawit-palm-oil/
Penilaian teknis perlu dilakukan untuk memberikan sebuah evaluasi dari kesesuaian tangka yang ada untuk terus beroperasi atau membuat keputusan yang digunakan untuk perbaikan dan perubahan pada tangki yang ada.

\section{TINJAUAN PUSTAKA}

\section{A. Storage Tank}

Menurut API 650, berdasarkan letak/posisi tangki dari atas permukaan tanah, tangki dapat dibedakan menjadi 2 jenis tangki, yaitu:

a. Aboveground tank, yaitu tangki penimbun yang terletak di atas permukaan tanah. Tangki jenis ini dapat berada dalam posisi horizontal (melebar) maupun dalam posisi vertikal (tegak).

b. Underground tank, yaitu tangki penimbun yang terletak di bawah permukaan tanah.

c. Semi burried tank, yaitu tangki setengah pendam, atau sebagian terdapat di bagian bawah permukaan tanah dan sebagian lain di atas permukaan tanah.

Tangki penyimpanan dapat diklasifikasikan menjadi dua bagian berdasarkan tekananan di dalamnya, yaitu:

1. Tangki Atmosferik

Tangki Atmosferik (Atmospheric Tank) adalah tangki timbun yang memiliki tekanan yang sangat rendah atau hampir sama dengan tekanan udara luar atau 1 atmosfer . 


\section{Tangki Timbun Bertekanan (Pressure Tank)}

Pressure tank adalah tangki yang menyimpan fluida dengan tekanan uap lebih dari 11,1 psi atau di atas atmosferik .

\section{B. Perlengkapan Tangki Timbun}

Bagian utama tangki terdiri atas atap (roof), dinding (shell), dasar (bottom), dan pondasi. Sedangkan perlengkapan untuk jenis tangki tegak adalah sebagai berikut, dengan ilustrasi terdapat pada Gambar 1 (Anonim1, 2014)

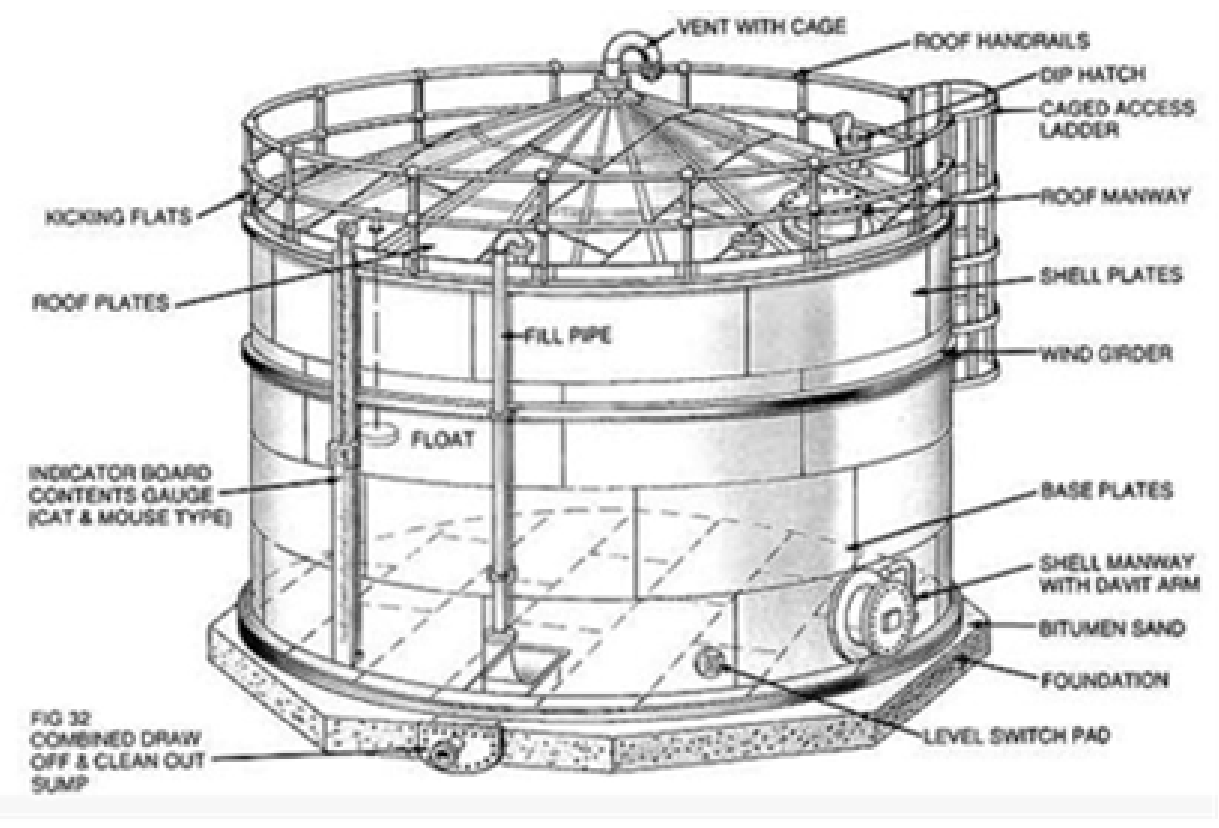

Gambar 1. Bagian-bagian tangki

1. Handrail (pagar pegangan) sebagai pagar di sekeliling atap tangki dan menuju pusat atap tangki.

2. Staircase (tangga spiral) sebagai alat yang digunakan naik ke atas tangki untuk kebutuhan operasi.

3. Shell Manhole dan Roof Manhole (lubang masuk orang pada dinding dan atap) sebagai perlengkapan untuk pemeliharaan atau perbaikan tangki.

4. Inlet dan outlet valve sebagai alat untuk masuk dan keluar cairan dalam tangki timbun.

5. Breather valve merupakan alat pernapasan untuk menjaga kondisi tekanan dalam tangki agar sesuai dengan ketentuan.

Untuk cairan kelas B \& C dikenal sebagai
Free Vent, untuk cairan kelas A dikenal sebagai P.V. Valve (Pressure Vacuum Valve).

6. Dip hatch, adalah lubang ukur yang berfungsi sebagai tempat pengukuran dan pengambilan contoh, yang terdapat di atap tangki produk kelas B dan C.

7. Slot dipping device, adalah lubang ukur yang berfungsi sebagai tempat pengukuran dan pengambilan contoh, yang terdapat pada atap tangki cairan kelas A.

8. Dip plate, adalah meja ukur pada bagian dasar tangki yang terletak tegak lurus dengan lubang ukur.

9. Water sprinkler atau water sprayer, digunakan untuk mendinginkan atap dan dinding tangki dengan air.

10. Level indicator, berfungsi sebagai pem- 
banding untuk rnengetahui ketinggian/ level cairan dalam tangki.

11. Grounding cable (kawat pentanahan), sebagai penyalur muatan listrik statis ke dalam tanah (harus mempunyai tahanan pentanahan di bawah 7 ohm).

12. ATG (Automatic Tank Gauge), sebagai alat ukur untuk mengetahui stok BBM yang ada di dalam tangki.

Selain itu, tangki juga harus dilengkapi dengan bund wall. Bund wall adalah bangunan atau dinding yang terbuat dari bata, batu, beton atau material setara lainnya, yang membentuk perimeter sebagai penahan cairan. Bund wall harus dirancang untuk dapat menampung tumpahan dan bocoran cairan yang digunakan, disimpan, atau sedang diproses di atas tanah dan untuk memfasilitasi operasi pembersihan. Selain sebagai sistem pencegahan polusi lingkungan, bund wall juga digunakan untuk pencegah kebakaran, product recovery, dan isolasi proses (Anonim2, 2007).

\section{API Std 653}

Terdapat beberapa standar internasional yang sudah umum dijadikan acuan dalam pemeriksaan teknis tangki timbun. Standar yang umum digunakan untuk pemeriksaan teknis tangki penimbun existing pada industri migas adalah mengacu kepada API Standard (Std) 653: Tank Inspection, Repair, Alteration, and Reconstruction. API Std 653 adalah standar acuan untuk inspeksi, perbaikan, perubahan, dan rekonstruksi tangki penimbun yang digunakan pada industri perminyakan dan kimia.

Standar ini mencakup tangki dengan material carbon steel dan low alloy steel yang dibuat berdasarkan API Std 650 (Welded Tanks for Oil Storage) dan pendahulunya API 12 C (Welded Oil Storage Tank). API Std 653 memberikan referensi persyaratan minimum untuk mempertahankan integritas tangki penimbun yang terletak di atas permukaan tanah (aboveground), bertekanan atmosferik, nonrefrigerated, dan dikonstruksi dengan sambungan menggunakan las atau rivet.

Inspeksi tangki penimbun yang sedang beroperasi perlu dilakukan agar potensi perubahan kondisi fisik tangki dapat diidentifikasi sebelum terjadinya kegagalan operasi yang disebabkan oleh kecacatan tangki. Metode evaluasi kelayakan operasi (suitability for service) sebagaimana terdapat pada API Std 653 section 4 membantu inspektur dalam melakukan inspeksi tangki penimbun. API Std 653 menyebutkan sejumlah faktor yang dipertimbangkan dalam evaluasi kelayakan operasi tangki penimbun, antara lain:

- Korosi internal karena produk yang disimpan atau air pada bottom tank

- Korosi eksternal karena paparan lingkungan

- $\quad$ Stress level dan allowable stress level

- Properties produk yang disimpan, seperti specific gravity, suhu, dan korosivitas

- Temperatur desain logam pada tangki

- Beban hidup external roof, angin, dan beban gempa

- Pondasi tangki, tanah, dan kondisi settlement

- Analisis kimia dan sifat mekanis material konstruksi

- Distorsi pada konstruksi tangki

- Kondisi operasi, seperti frekuensi dan kecepatan pengisian/ pengosongan

\section{Evaluasi Shell Tangki (API 653)}

Korosi dapat didefinisikan sebagai perusakan suatu material (terutama logam) karena bereaksi dengan lingkungannya. Kondisi yang terjadi pada saat logam bereaksi dengan lingkungan sebagian logam akan menjadi oksida, sulfida atau hasil reaksi lain yang da- 
pat larut dengan lingkungan. Efek yang diperoleh dari reaksi logam dengan lingkungan adalah sebagian logam akan hilang menjadi suatu senyawa yang lebih stabil. Pada kondisi alam bebas logam pada umumnya berupa senyawa, karena itu peristiwa korosi juga dapat dianggap sebagai peristiwa kembalinya logam pada bentuk sebagaimana terdapat di alam (Trethewey, K.R dkk, 1991).

Cacat, penipisan, atau kondisi lain yang mungkin disebabkan oleh perubahan kondisi operasi, pemindahan, atau kecepatan korosi yang lebih besar dari Corrosion Allowance harus dievaluasi untuk kelayakan pemakaian. Analisis dan evaluasi kondisi cangkang harus mempertimbangkan segala kemungkinan kombinasi dan kondisi pembebanan. Tekanan akibat tinggi tekan fluida, tekanan internal dan eksternal, beban angin dan gempa, beban hidup atap, nozzle, settlement, dan beban tambahan.

Korosi shell terjadi dalam berbagai bentuk dan tingkat kerusakan dapat menyebabkan kehilangan metal secara merata baik pada permukaan yang luas ataupun permukaan yang terbatas. Pitting juga mungkin terjadi, namum biasanya bukan merupakan ancaman serius bagi integritas struktur secara keseluruhan kecuali jika muncul dengan pitting yang letaknya saling berdekatan. Jika persyaratan tebal tidak dapat dipenuhi, area yang terkorosi atau rusak harus dilakukan reparasi, atau pengurangan tinggi level cairan yang diizinkan, atau tangki tidak dipakai lagi.

Untuk menentukan tebal aktual rata-rata shell, tentukan daerah-daerah pada shell dimana terlihat korosi atau dimana daerah yang paling memungkinkan terjadi korosi. Titik-titik pengukuran dapat ditentukan secara acak atau menggunakan grid system dengan membagi shell secara melintang menjadi beberapa wilayah pengukuran (course) yang memiliki ketinggian yang sama. Tebal aktual tangki diukur dengan menggunakan ultrasonic test.
Metode penentuan ketebalan aktual menggunakan acuan API Std 653 dapat digambarkan di Gambar 2.

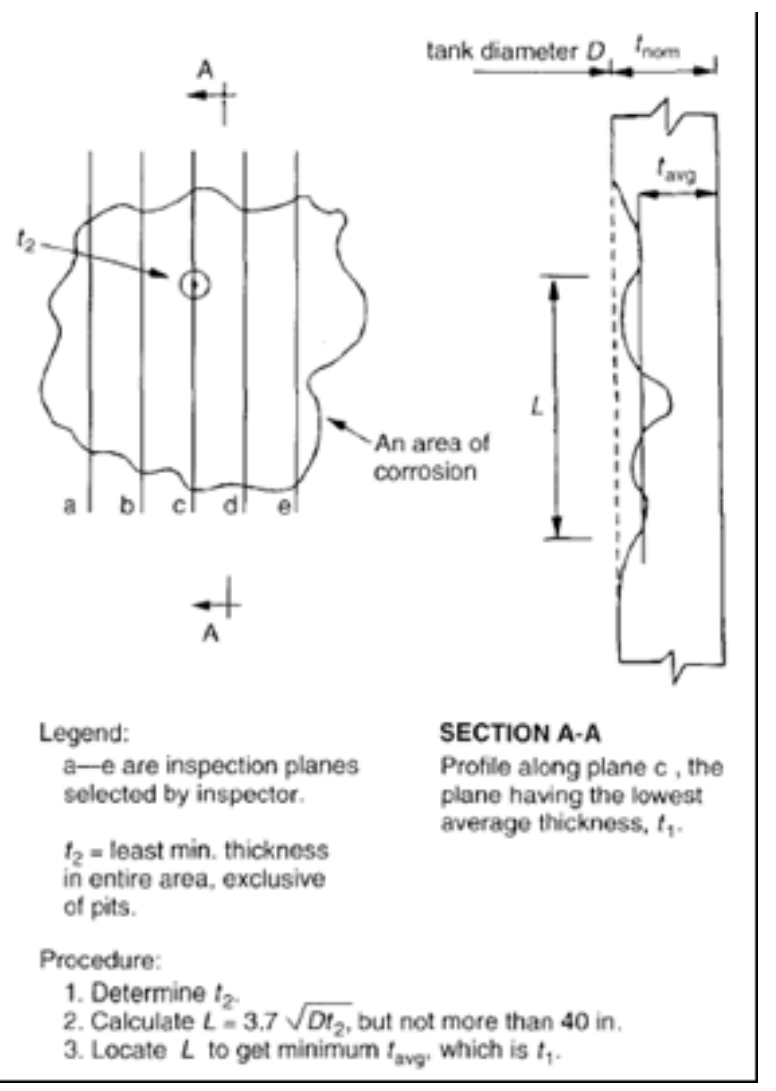

Gambar 2. Metode penentuan ketebalan aktual

Keterangan gambar:

$L$ : panjang vertikal maksimum pengambilan titik sampling (inci) dimana diasumsikan terjadi penipisan tangki yang dapat mewakili satu area

$D$ : diameter tangki ( $\mathrm{ft}$ )

: ketebalan terkecil (in) pada area yang diasumsikan terjadi korosi paling besar

Shell dibagi menjadi beberapa area, umumnya dibagi menjadi 5 area/course dengan ketinggian yang sama. Lalu, dipilih titik secara acak untuk menentukan, yaitu ketebalan terkecil tangki pada satu course pada shell tangki. Inspektur menentukan posisi mana pada tangki yang akan dilakukan pengukuran ketebalan . Umumnya, seorang inspektur akan melihat dimana bagian tangki yang berpotensi besar 
mengalami korosi. Di area itulah biasanya dilakukan pengukuran ketebalan.

Setelah diidentifikasi, $L$ dihitung dengan menggunakan persamaan (1)

$$
L=\sqrt{3,7 D t_{2}}
$$

Tarik garis lurus vertikal sepanjang $L$ dengan titik tengah adalah lokasi pengukuran . Bagi garis $L$ dengan minimal 5 titik dengan jarak yang sama. Ukur ketebalan tangki pada setiap titik (yang sudah ditentukan di poin 3) dengan Ultrasonic Thickness Meter (UTM). Hasil ratarata ketebalan pada semua titik pengukuran di garis $L$ merupakan . Ulangi untuk coursecourse selanjutnya sehingga akan diperoleh untuk masing-masing course.

Sedangkan untuk perhitungan dilakukan sebagai berikut:

a. Untuk menentukan tebal minimum yang diperbolehkan untuk seluruh shell tangki, dapat dihitung dengan persamaan (2):

$$
t_{\min }=\frac{2,6(H-1) D G}{S E}
$$

b. Untuk menentukan tebal minimum yang diperbolehkan untuk bagian lain dari shell tangki (seperti korosi lokal), dapat dihitung dengan persamaan (3):

$$
t_{\min }=\frac{2,6 H D G}{S E}
$$

Dengan:

$\mathrm{t}_{\text {min }}$ : Ketebalan minimum yang dapat diterima, dalam inci, yang diperoleh dari rumus di atas; tidak boleh kurang dari 0.1 inci untuk setiap lapis.

$D$ : Diameter nominal (ft).

$H \quad$ : Tinggi ( $\mathrm{ft}$ )
- dari dasar course tangki hingga level cairan desain maksimum (jika mengevaluasi seluruh shell course; atau

- dari dasar panjang $L$ area yang terkorosi parah pada setiap lapis sampai level cairan desain maksimum; atau

- dari titik terendah pada posisi manapun yang ingin ditinjau sampai level cairan liquid desain maksimum

G : Specific gravity terbesar isi tangki

$S \quad$ : Tegangan izin maksimum dalam pounds per inci persegi; pakai yang terkecil antara 0.80Y atau 0.429T untuk dasar dan course kedua; pakai yang terkecil antara $0.88 \mathrm{Y}$ atau $0.472 \mathrm{~T}$ untuk course lainnya. Nilai tegangan izin shell yang diperbolehkan terdapat pada tabel 4-1 API Std 653 untuk material yang terdapat pada API Std 12C dan Std 650 edisi saat ini dan edisi-edisi sebelumnya.

$Y \quad$ : yield strength/tegangan leleh minimum pelat; pakai 30,000 psi jika tidak diketahui.

$T$ : tensile strength/kuat tarik minimum dari pelat, terdapat pada tabel 4-1 API Std 653 atau 80.000 psi (gunakan yang nilainya lebih kecil); gunakan 55,000 psi jika tidak material tidak diketahui.

$E$ : efisiensi hubungan mula-mula tangki. Gunakan Tabel 4-2 API Std 653 jika E mula-mula tidak diketahui. $E=1,0$ untuk mengevaluasi ketebalan retirement pada pelat terkorosi, untuk jarak dari las atau sambungan setidaknya yang terbesar dari 1 inci atau dua kali tebal pelat.

Kriteria kelayakan operasi:

- `Nilai harus lebih besar atau sama dengan $\mathrm{t}_{\text {min }}$, dengan mempertimbangkan semua beban lain sesuai dengan API Std 653 sec- 
tion 4.3.3.5 (wind-induced buckling; beban seismik; operasi pada suhu lebih dari $200^{\circ} \mathrm{F}$; vacuum-induced external pressure; beban eksternal yang disebabkan oleh perpipaan, peralatan pemasangan tangki, hold down lugs, dan lain-lain seperti beban angin dan beban karena settlement)

- "Nilai harus lebih besar atau sama dengan 60\% dari ; dan Corrosion allowance yang diperlukan sampai waktu inspeksi selanjutnya harus ditambahkan kepada dan 60 $\%$ dari .

Pada tangki penimbun juga memiliki kemungkinan terdapat pitting yang dapat mempengaruhi pengukuran ketebalan tangki, akan tetapi untuk pitting yang tersebar luas dapat diabaikan jika:

a. Tidak ada pitting yang menyebabkan tebal sisa shell kurang dari setengah ( $1 / 2)$ kali tebal minimum yang dapat diterima (tidak termasuk corossion allowance); dan

b. Jumlah total dimensinya sepanjang setiap garis vertikal tidak melebihi 2 inci dalam setiap 8 inci panjang, seperti yang ditunjukkan pada Gambar 3

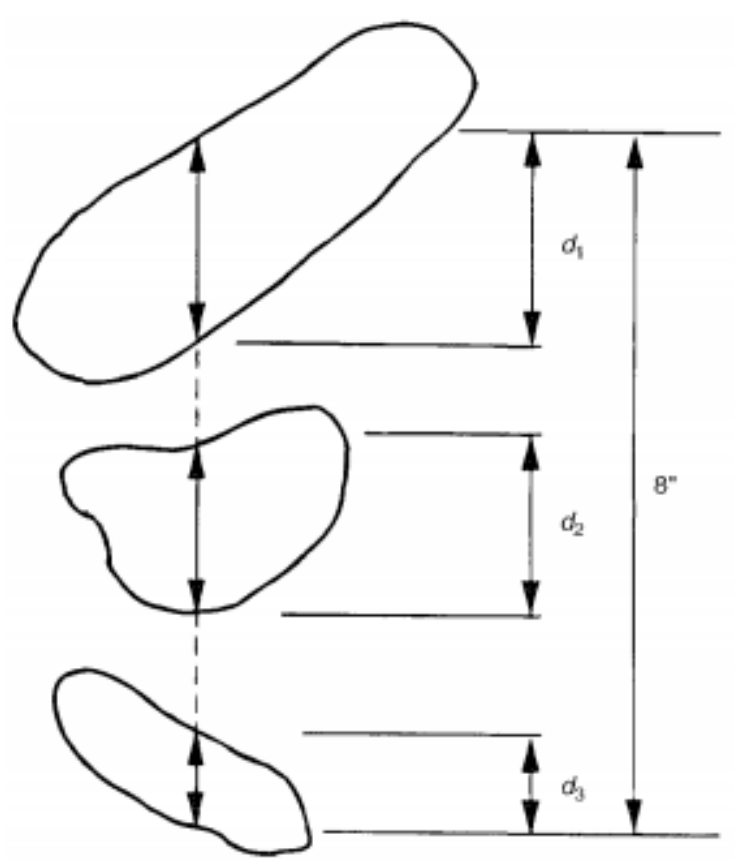

$d_{1}+d_{2}+d_{3} \ldots \leq 2^{*}$
Gambar 3. Metode pengukuran pitting

\section{E. Ultrasonic Testing (ASME Section V)}

Ultrasonic Testing (UT) merupakan salah satu metode nondestructive examination (NDE) yang menggunakan energi suara frekuensi tinggi untuk melakukan proses pengujian atau proses pengukuran. Prosedur pengujian dan pengukuran dengan menggunakan metode UT umumnya mengacu kepada standar ASME Section V Article 5. Dalam melakukan pengujian menggunakan metode UT pada peralatan/instalasi di industri migas Indonesia, prosedur pengujian NDE/NDT (termasuk di dalamnya metode UT) harus mendapatkan pengesahan terlebih dahulu oleh pemerintah (cq. Ditjen Migas). Prosedur yang sudah disahkan ini akan menjadi acuan bagi perusahaan untuk melakukan pengujian NDT.

Alat yang digunakan untuk pengukuran ketebalan adalah Ultrasonic Thickness Meter (UTM), dimana ketebalan shell/roof tangki penimbun dapat langsung diketahui karena hasilnya langsung ditampilkan pada layar UTM.

\section{F. Remaining Life}

Dalam standar API 653 perhitungan laju korosi dan remaining life tangki dapat dilakukan dengan menggunakan formula (4) dan (5) sebagai berikut:

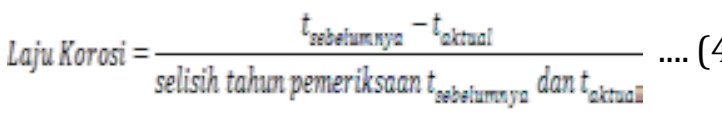

Remaining life $($ tahun $)=\frac{t_{\text {aktual }}-t_{\text {required }}}{\text { corrosion rate }}$

\section{Dimana}

$t_{\text {aktual }}$ : ketebalan (dalam inci atau $\mathrm{mm}$ ), yang diukur pada waktu inspeksi 
$t_{\text {required }}:$ ketebalan yang dibutuhkan (dalam inci atau $\mathrm{mm}$ ), pada lokasi yang sama atau komponen seperti pengukuran aktual yang dihitung dari desain sebelum corrosion allowance ditambahkan.

\section{METODE PENELITIAN}

Metode yang dilakukan terdiri dari beberapa tahap. Petama, studi literatur dengan mencari data serta mencari persamaan yang digunakan dalam perhitungan. Kedua, mengambil data di lapangan dengan melakukan pengukuran ketebalan shell tangki menggunakan metode NDT, dan selanjutnya dilakukan analisis terhadap laju korosi dan sisa umur tangki penimbunnya.

\section{HASIL PENELITIAN DAN PEMBAHASAN}

\section{A. Data Tangki}

\begin{tabular}{|c|c|}
\hline User & : PPSDM Migas \\
\hline Location & : Refinery PPSDM Migas \\
\hline Object & : Storage Tank \\
\hline Tag & : T-XYZ \\
\hline Type of Tank & $\begin{array}{l}\text { : Vertical above grou } \\
\text { tank }\end{array}$ \\
\hline Service & : Pertasol CA \\
\hline Specific Gravity & : 0.71 \\
\hline Capacity & $: \quad 102.57 \mathrm{~m}^{3}$ \\
\hline Outside Diameter & : $5,981 \mathrm{~mm}$ \\
\hline Height & : $3,650 \mathrm{~mm}$ \\
\hline Max Liquid Level & : $3,632 \mathrm{~mm}$ \\
\hline Design Pressure & : Atmospheric \\
\hline Design Temp. & : $34^{\circ} \mathrm{C}$ \\
\hline Material & : Unknown \\
\hline Manufacturer & : Unknown \\
\hline Year Built/Used & : 1984/1984 \\
\hline
\end{tabular}

\section{B. Pengukuran Tebal Tangki}

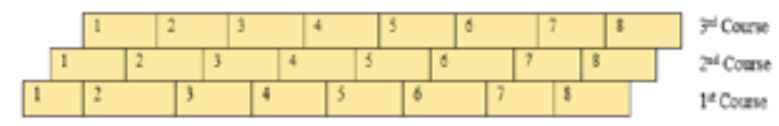

MEASUREMENTS POINT

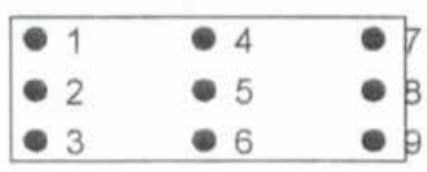

Gambar 4. Daerah pengukuran shell thickness

Pengukuran dilakukan di masing-masing $\mathrm{Co}^{-}$ urse, dan masing-masing course dibagi menjadi 8 point atau sambungan dan masingmasing point dilakukan pengukuran sebanyak 9 tempat pengukuran.

Dari hasil pengukuran didapatkan hasil tebal aktual minimal masing-masing course seperti Tabel 1.

Tabel 1. Hasil Pengukuran Shell Thickness

\begin{tabular}{|c|c|}
\hline Course & Tebal aktual $\left(\mathrm{t}_{\mathrm{act}}\right)$ \\
\hline $1^{\text {st }}$ & $4.50 \mathrm{~mm}$ \\
\hline $2^{\text {nd }}$ & $4.10 \mathrm{~mm}$ \\
\hline $3^{\text {rd }}$ & $4.40 \mathrm{~mm}$ \\
\hline
\end{tabular}

Sedangkan perhitungan tebal minimal shell tangki $\left(t_{\min }\right)$ adalah sebagai berikut:

\section{B. Data Tangki:}

$\begin{array}{ll}\text { H liquid } & : 11.917 \text { feet } \\ \text { D } & : 19.623 \text { feet } \\ \mathrm{H} 1^{\text {st }} \text { course } & : 4,000 \text { feet } \\ {\mathrm{H} 2^{\text {nd }} \text { course }}^{\text {rd }} & : 4,003 \text { feet } \\ \mathrm{H}^{\text {rd }} \text { course } & : 3,609 \text { feet } \\ \text { G } & : 0.71\end{array}$


Material : unknown

$\mathrm{S} 1^{\text {st }}, 2^{\text {nd }}$ course $\quad: 23595 \mathrm{lbf} / \mathrm{in}^{2}$

$\mathrm{S} 3^{\text {rd }}$ course $\quad: 25960 \mathrm{lbf} / \mathrm{in}^{2}$

Dengan menggunakan rumus (6) berikut:

$$
t_{\min }=\frac{2,6(H-1) D G}{S E}
$$

Maka didapatkan hasil seperti Tabel 2, dan sesuai API 653 hasil pengukuran ketebalan tiap course tidak boleh lebih kecil dari 0.1 inchi atau $2,54 \mathrm{~mm}\left(t_{\text {req }}\right)$

Tabel 2. Hasil Perhitungan Tebal Shell Minimum (mm)

\begin{tabular}{ccccc}
\hline Course & $\mathbf{t}_{\min }$ & $\mathbf{t}_{\text {req }}$ & $\mathbf{t}_{\text {act }}$ & Result \\
\hline $1^{\text {st }}$ & 0,608 & 2,540 & 4,50 & acceptable \\
\hline $2^{\text {nd }}$ & 0,385 & 2,540 & 4,10 & acceptable \\
\hline $3^{\text {rd }}$ & 0,147 & 2,540 & 4,40 & acceptable \\
\hline
\end{tabular}

Dari hasil perhitungan di atas maka ketebalan pelat tiap course adalah masih layak digunakan untuk ketinggian operasi cairan 11,917 ft dari dasar tangki.

\section{Analisis Laju Korosi dan Umur Sisa}

Hasil perhitungan laju korosi (corrosion rate) ditunjukkan dalam Tabel 3. Di mana tebal shell sebelumnya diambil 5 tahun sebelum tebal aktual dilakukan pengukuran.

Tabel 3. Hasil Analisis Laju Korosi

\begin{tabular}{|l|c|c|c|}
\hline Course & $\mathbf{t}_{\text {act }}(\mathbf{m m})$ & $\begin{array}{c}\mathbf{t}_{\text {prev }} \\
(\mathbf{m m})\end{array}$ & $\begin{array}{c}\text { Corrosion rate } \\
(\mathbf{m m p y})\end{array}$ \\
\hline $\mathbf{1}^{\text {st }}$ & 4.50 & 4.80 & 0.06 \\
\hline $\mathbf{2}^{\text {nd }}$ & 4.10 & 4.30 & 0.04 \\
\hline $\mathbf{3}^{\text {rd }}$ & 4.40 & 4.80 & 0.08 \\
\hline
\end{tabular}

Sedangkan hasil Analisis dati umur sisa ditampilkan dalam Tabel 4.

Tabel 4. Hasil Analisa Remaining Life

\begin{tabular}{|l|c|c|c|c|}
\hline Course & $\mathrm{t}_{\min }$ & $t_{\text {req }}$ & $\mathrm{t}_{\text {act }}$ & Remaining Life \\
\hline $\mathbf{1}^{\text {st }}$ & 0,608 & 2,540 & 4,50 & 32.67 year \\
\hline $\mathbf{2}^{\text {nd }}$ & 0,385 & 2,540 & 4,10 & 39.00 year \\
\hline $\mathbf{3}^{\text {rd }}$ & 0,147 & 2,540 & 4,40 & 23.25 year \\
\hline
\end{tabular}

Tabel 5. Hasil Analisis Laju Korosi dan Umur Sisa

\begin{tabular}{|l|c|c|}
\hline Course & Corrosion rate & Remaining Life \\
\hline $\mathbf{1}^{\text {st }}$ & 0.06 mmpy & 32.67 year \\
\hline $\mathbf{2}^{\text {nd }}$ & 0.04 mmpy & 39.00 year \\
\hline $\mathbf{3}^{\text {rd }}$ & 0.08 mmpy & 23.25 year \\
\hline
\end{tabular}

Dari hasil perhitungan di atas maka tangki timbun T-XYZ masih layak operasi sampai 5 tahun ke depan dari pengambilan data tebal shell actual terakhir.

\section{KESIMPULAN}

Dari hasil Analisa dan perhitungan didapatkan bahwa tangki timbun masih layak untuk dioperasikan pada level tinggi cairan sesuai yang disyaratkan. Sedangkan hasil analisis menunjukkan besar laju korosi pada masingmasing dinding tangki course $1^{\text {st }}$, course $2^{\text {nd }}$ dan course $3^{\text {rd }}$ adalah $0.06,0.04$ dan 0.08 mmpy. Dan hasil analisis menunjukkan umur sisa untuk masing-masing dinding tangki $\mathrm{Co}^{-}$ urse $1^{\text {st }}$, course $2^{\text {nd }}$ dan course $3^{\text {rd }}$ adalah 32,67 , 39,00 dan 23.25 tahun. Dari hasil analisa tersebut dapat dinyatakan bahwa tangki timbun masih layak operasi sampai inspeksi berikutnya atau 5 tahun yang akan datang dari hasil inspeksi terahir. 


\section{DAFTAR PUSTAKA}

Anonim1, Tangki dan Fasilitasnya, Cepu, Pusdiklat Migas, 2014

Anonim2, Bunding and spill management, Liquid Storage Guideline, Environment Protection Authority, 2007

API Std $65012^{\text {th }}$, Edition, Welded Tank for Oil Storage, 2013

API Std $6535^{\text {th }}$ Edition, Tank Inspection, Repair, Alteration and Reconstruction, 2014

ASME Section V 2010 edition, Nondestructive Examination, 2010

https://almeganews.wordpress.com/2019/08/26/kalibrasi-tangki-minyak-kelapa-sawitpalm-oil/ diunduh tanggal 18 Oktober 2020

Trethewey, K.R dan Chamberlain, J, Korosi Untuk Mahasiswa dan Rekayasawan, PT Gramedia Pustaka Utama, Jakarta, 1991 